\title{
Competition and Product Cycles with Non-Diversifiable Risk
}

Tapio Palokangas (Tapio.Palokangas@helsinki.fi)

\section{Approved by}

Arkady Kryazhimskiy

Program Leader, DYN

July 2006 Institute, its National Member Organizations, or other organizations supporting the work. 


\section{Contents}

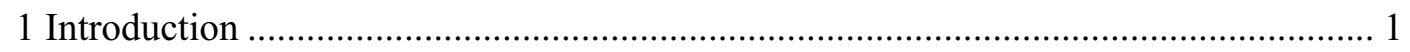

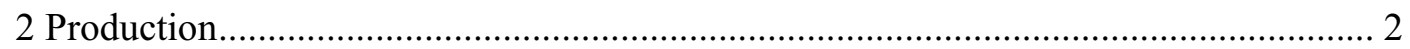

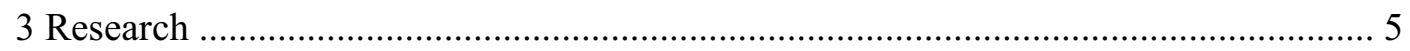

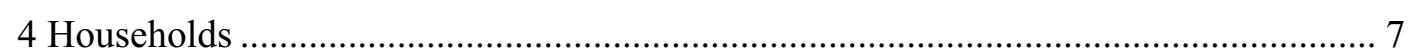

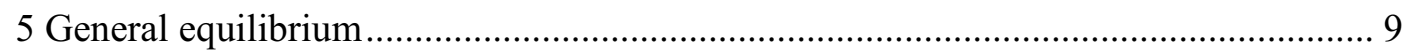

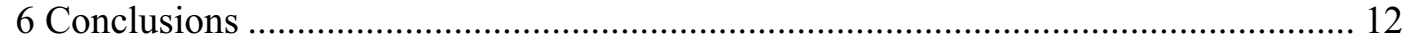

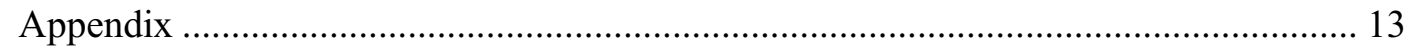

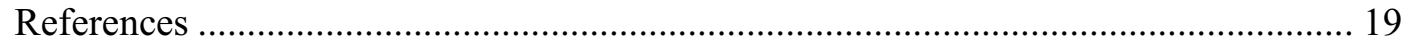




\title{
Competition and Product Cycles with Non-Diversifiable Risk
}

\author{
Tapio Palokangas* \\ University of Helsinki and HECER
}

\begin{abstract}
This paper analyzes the growth effects of competition in a productcycle model where R\&D firms both innovate and imitate and households are subject to non-diversifiable risk. I prove that product market competition promotes growth when the initial level of competition is high enough. In contrast to the earlier product-cycle models with diversifiable risk, I show also the following. Some positive profits are necessary for technological change. The larger the proportion of industries subject to price competition, the slower economic growth.
\end{abstract}

Corresponding author:

Tapio Palokangas, Department of Economics, P.O. Box 17 (Arkadiankatu 7), FIN-00014 University of Helsinki, Finland. Phone +358 9191 28735, Fax +358 9191 28736, Email: Tapio.Palokangas@helsinki.fi

${ }^{*}$ The author thanks Vesa Kanniainen, Juuso Välimäki, Otto Toivanen, Mikko Mustonen and the participants of the IIASA seminar, Laxenburg, for helpful comments, and the Academy of Finland for the opportunity to visit IIASA in July 2006. Financial support from The Yrjö Jahnsson Foundation is gratefully acknowledged. 


\section{Introduction}

This paper considers the growth and welfare effects of competition when households cannot wholly diversify their investment risk and economic growth is characterized by product cycles as follows. Through the development of new products, an innovator achieves a temporary advantage earning monopoly profits. This advantage ends when an imitator succeeds in copying the innovation, enters the market and starts competing with the innovator.

Product cycle models start from Segerstrom (1991), who assumes that (i) incumbents and outsiders have the same costs of innovation, and (ii) households eliminate investment risk wholly by diversification. Assumption (i) leads to leapfrogging: innovations will always be performed by outsiders and the current industry leaders will be wholly replaced. To eliminate this unrealistic outcome, Aghion et al. (1997, 2001) construct models where technological laggards must first catch up with the leading-edge technology before battling "neck-to-neck" for technological leadership in the future. They represent competition by the elasticity of substitution between firms' products and show that competition has in general a positive effect on economic growth. Mukoyama (2003) constructs a model in which only leaders can conduct next-round innovation, while outsiders can become leaders by imitation. He represents competition by the relative proportion of competing industries and shows that competition very commonly promotes economic growth.

The three papers above are based on Segerstrom's assumption (ii) of full diversification. Wälde (1999a, 1999b) shows that with non-diversifiable risk investment decisions are made by households rather than firms, and the equilibrium conditions differ substantially. To examine competition policy with non-diversifiable risk, I extend Wälde's one-industry growth model for an economy with many industries and incorporate Mukoyama's (2003) assumptions on imitation and cumulative technology into it. The model of this study is therefore characterized as follows:

(i) Labor is homogeneous and inelastically supplied. It is used in innovation, imitation or the production of the intermediate goods.

(ii) Competitive firms produce the consumption good from a great number of intermediate goods according to Cobb-Douglas technology. 
(iii) Firms' products are imperfect substitutes. A successful innovator of a new technology crowds out all products made with old technology and becomes a monopolistic producer until its technology is imitated. A successful imitator starts producing a substitute for the innovator's product and establishes an innovation race with the incumbent producers. Imitation is necessary for an outsider to become an innovator.

(iv) R\&D firms finance their expenditure by issuing shares. The households save only in these shares. Each R\&D firm distributes its profit among those who had financed it in proportion to their investment in the firm.

The remainder of this paper is organized as follows. Sections 2 and 3 consider firms in production and R\&D. Section 4 examines households deciding on saving. Section 5 considers the effects of competition.

\section{Production}

I assume a great number of intermediate-good industries that are placed over the limit $[0,1]$. Industry $j \in[0,1]$ contains intermediate-good firms $\kappa=1, \ldots, a_{j}$. The representative consumption-good firm makes its output $y$ from the products of all intermediate-good firms through technology

$$
\log y=\int_{0}^{1} \log \left[B_{j} x_{j}\right] d j, \quad x_{j}=\left[a_{j}^{-1 / \varepsilon} \sum_{\kappa=1}^{a_{j}} x_{j \kappa}^{1-1 / \varepsilon}\right]_{,}^{\varepsilon /(\varepsilon-1)} \quad \varepsilon>1,
$$

where $B_{j}$ is the productivity parameter in industry $j, a_{j}$ the number of firms in industry $j, x_{j}$ the quantity of intermediate good $j, x_{j \kappa}$ the output of firm $\kappa$ in industry $j$, and $\varepsilon$ the elasticity of substitution between the products in the same industry. ${ }^{1}$ The consumption-good firm maximizes its profit

$$
\Pi^{c} \doteq P y-\int_{j \in[0,1]} \sum_{\kappa=1}^{a_{j}} p_{j \kappa} x_{j \kappa} d j
$$

by its inputs $x_{j}$, taking the output price $P$ and the input prices $\left\{p_{j \kappa}\right\}$ as fixed. I normalize total consumption expenditure $P y$ at unity. Because the

\footnotetext{
${ }^{1}$ With the specification (1), the price $p_{j}$ for the composite product of industry $j$ will (in the symmetric equilibrium $p_{j \kappa}=p_{j 1}$ ) be independent of the number of producers in that industry, $a_{j}$. Otherwise, the effect of $a_{j}$ on $p_{j}$ would excessively complicate the analysis.
} 
consumption-good firm is subject to constant returns to scale, we then obtain

$$
\begin{aligned}
& P y=1, \quad \Pi^{c}=0, \quad p_{j} x_{j}=1 \text { and } p_{j}=\left[\frac{1}{a_{j}} \sum_{\kappa=1}^{a_{j}} p_{j \kappa}^{1-\varepsilon}\right]^{1 /(1-\varepsilon)} \text { for all } j, \\
& x_{j \kappa}=\frac{\partial p_{j}}{\partial p_{j \kappa}} x_{j}=\frac{1}{a_{j}}\left(\frac{p_{j}}{p_{j \kappa}}\right)^{\varepsilon} x_{j}=\frac{1}{a_{j}} p_{j}^{\varepsilon-1} p_{j \kappa}^{-\varepsilon} \text { for all } j \text { and } \kappa,
\end{aligned}
$$

where $p_{j}$ is the price of the composite product $x_{j}$.

I assume that all intermediate-good firms produce one unit of their output from one labor unit. Technological change is random. I assume that a successful innovator in industry $j$ makes a perfect substitute for intermediate good $j$ that is composed of the outputs all incumbent firms with older technology in industry $j .{ }^{2}$ The innovator's profit is $\Pi_{j 1}=\left(p_{j 1}-w\right) x_{j 1}$, where $p_{j 1}$ is its output price, $x_{j 1}$ its output (= labor input) and $w$ is the wage.

The innovator's product provides exactly the constant $\mu>1$ times as many services as the intermediate good of earlier generation. Firm $\kappa$ of earlier generation earns the profit $\Pi_{j \kappa}^{o}=\left(p_{j \kappa}^{o}-w\right) x_{j \kappa}^{o}$, where $p_{j \kappa}^{o}$ is its output price and $x_{j \kappa}^{o}$ its output. The innovator pushes the old firms out of the market by choosing its price $p_{j 1}$ so that these earn no profit, $\Pi_{j \kappa}^{o}=0$ and $p_{j \kappa}^{o}=w$. This and (2) yield $p_{j 1} / \mu=p_{j}^{o}=p_{j \kappa}^{o}=w$, the mark-up rule $p_{j 1}=\mu w$ and the innovator's output and profit as follows:

$$
\begin{aligned}
& x_{j}=x_{j 1}=1 / p_{j 1}=1 /(\mu w) \text { and } \\
& \Pi_{j 1}=\left(p_{j 1}-w\right) x_{j 1}=(1-1 / \mu) p_{j 1} x_{j 1}=1-1 / \mu \doteq \Pi \text { for } a_{j}=1 .
\end{aligned}
$$

The innovator is the first leader (i.e. the first incumbent producer) in industry $j$. A successful imitator of the state-of-art good is able to make a close substitute for the product of the innovator. Thus with each imitation, the number of leaders and products increases by one. I assume that all leaders $1, \ldots, a_{j}$ in industry $j$ behave in Bertrand manner, taking each other's prices as given. Given (1) and (2), leader $\kappa$ in industry $j$ maximizes its profit

$$
\pi_{j \kappa}=p_{j \kappa} x_{j \kappa}-w x_{j \kappa}=\left(p_{j \kappa}-w\right) x_{j \kappa},
$$

by its price $p x_{j \kappa}$, assuming that the prices $p_{j \imath}$ for the other leaders $\imath \neq \kappa$ in industry $j$ are kept constant. It therefore sets the wage $w$ equal to the

\footnotetext{
${ }^{2}$ This assumption is in line with technology (1), because $x_{j}=x_{j 1}$ for $a_{j}=1$.
} 
marginal product of labor. Noting (2), this leads to the first-order condition

$$
\begin{aligned}
\frac{\partial \pi_{j \kappa}}{\partial p_{j \kappa}} & =x_{j \kappa}+\left(p_{j \kappa}-w\right)\left[\frac{\partial x_{j \kappa}}{\partial p_{j \kappa}}+\frac{\partial x_{j \kappa}}{\partial p_{j}} \frac{\partial p_{j}}{\partial p_{j \kappa}}\right] \\
& =x_{j \kappa}+\left(p_{j \kappa}-w\right)\left[-\varepsilon \frac{x_{j \kappa}}{p_{j \kappa}}+(\varepsilon-1) \frac{x_{j \kappa}}{p_{j}} \frac{1}{a_{j}}\left(\frac{p_{j}}{p_{j \kappa}}\right)^{\varepsilon}\right] \\
& =x_{j \kappa}\left\{1+\left(1-\frac{w}{p_{j \kappa}}\right)\left[-\varepsilon+\frac{\varepsilon-1}{a_{j}}\left(\frac{p_{j}}{p_{j \kappa}}\right)^{\varepsilon-1}\right]\right\}=0 .
\end{aligned}
$$

Because the conditions (2) and (5) hold for all $\kappa=1, \ldots, a_{j}$, the symmetry $p_{j \kappa}=p_{j}$ holds throughout all $\kappa$. This, (1), (2), (4) and (5) yield

$$
\begin{aligned}
& p_{j \kappa} / w=\left\{1-\left[\varepsilon+(1-\varepsilon) / a_{j}\right]^{-1}\right\}^{-1} \doteq \Phi\left(a_{j}\right), \quad \Phi^{\prime}<0, \quad a_{j} p_{j \kappa} x_{j \kappa}=1, \\
& \pi_{j \kappa}=\left(p_{j \kappa}-w\right) x_{j \kappa}=\left[1-\Phi\left(a_{j}\right)^{-1}\right] p_{j \kappa} x_{j \kappa}=\left[1-\Phi\left(a_{j}\right)^{-1}\right] / a_{j}, \\
& x_{j}=a_{j} x_{j \kappa}=1 / p_{j \kappa}=1 /\left[\Phi\left(a_{j}\right) w\right] .
\end{aligned}
$$

In order to make product market competition effective, I assume that the entry of the second leader decreases the first leader's mark-up:

$$
\mu>\Phi(2) \text {. }
$$

If anyone invests in imitative R\&D to enter an industry with one leader, then his prospective profit is $\left.\pi_{j \kappa}\right|_{a_{j}=2}$, but if he invests (with the same cost) in imitative $R \& D$ to enter an industry with more than two leaders, then his prospective profit is $\left.\pi_{j \kappa}\right|_{a_{j}>2}$. Because, by (6), the profit is smaller with more than two leaders, $\left.\pi_{j \kappa}\right|_{a_{j}=2}>\left.\pi_{j \kappa}\right|_{a_{j}>2}$, investors invest in imitative R\&D only to enter in one-leader industries. Thus, each industry has one or two leaders. In one-leader industries the followers imitate and in two-leader industries the leaders innovate. I denote the set of one-leader industries by $\Theta \subset[0,1]$, and the relative proportion of one-leader (two-leader) industries, $\alpha(\beta)$ by

$$
\alpha=\int_{j \in \Theta} d j, \quad \beta \doteq \int_{j \notin \Theta} d j=1-\alpha .
$$

Noting $a_{j}=2,(3),(6),(7)$ and (8), a firm's profit $\pi(\Pi)$ and and total output $x_{\alpha}\left(x_{\beta}\right)$ in one-leader (two-leader) industry are given by

$\left.\Pi_{j}\right|_{j \in \Theta}=\Pi,\left.\quad \Pi_{j \kappa}\right|_{j \notin \Theta, a_{j}=2} \doteq[1-1 / \Phi(2)] / 2 \doteq \pi \in(0, \Pi / 2), 1 / \Phi(2)=1-2 \pi$, $x_{\beta}=\left.x_{j}\right|_{j \notin \Theta, a_{j}=2}=\frac{1}{\Phi(2) w}=\frac{1-2 \pi}{w}>x_{\alpha}=\left.x_{j}\right|_{j \in \Theta}=\frac{1}{\mu w}=\frac{1-\Pi}{w}$. 
The higher the elasticity of substitution between the products, $\varepsilon$, the closer $\Phi(2)$ to its lower limit 1 and the smaller $\pi .^{3}$ There are now two measures of competition: a competing firm's profit $\pi$ and the relative proportion of the competing (two-leader) industries, $\beta$. The purpose of this paper is to examine the growth and welfare effects of these.

Noting (1), (3), (8) and (9), and summing up throughout all firms and industries, one obtains that the employment of labor in production, $x$, and total output $y$ are determined as follows:

$x \doteq \alpha x_{\alpha}+(1-\alpha) x_{\beta}=\frac{\varphi}{w}, \varphi(\alpha, \pi) \doteq(1-\Pi) \alpha+(1-\alpha)(1-2 \pi)<1-2 \pi$,
$\frac{\partial \varphi}{\partial \alpha}=2 \pi-\Pi<0, \quad \frac{\partial \varphi}{\partial \pi}=2(\alpha-1)<0, \quad x_{\alpha}=(1-\Pi) \frac{x}{\varphi}, \quad \frac{\partial}{\partial \pi}\left(\frac{x_{\alpha}}{x}\right)>0$,
$x_{\beta}=(1-2 \pi) \frac{x}{\varphi}>x_{\alpha}, \quad \frac{\partial}{\partial \pi}\left(\frac{x_{\beta}}{x}\right)=(2 \pi-1) \frac{x}{\varphi^{2}} \frac{\partial \varphi}{\partial \pi}-2 \frac{x}{\varphi}=2(\Pi-1) \frac{\alpha x}{\varphi^{2}}<0$,

where $x$ is employment and $\varphi=w x$ wage expenditure. A decrease in a competing firm's profit $\pi$ increases employment $x$ and total wages in production, $\partial \varphi / \partial \pi<0$. Because competing industries $j \notin \Theta$ employ more than monopoly industries $j \in \Theta$ (i.e. $x_{\beta}>x_{\alpha}$ ), a smaller proportion $\alpha$ of monopoly industries raises employment $x$ and total wages $\varphi$ in production.

\section{Research}

There are three types of R\&D firms: the first leader (successful innovator), which I call firm 1, the second leader (successful imitator), which I call firm 2 , and followers, which I call firm 0 . In two-leader industry $j \notin \Theta$, firms 1 and 2 innovate and no firm imitates. The technological change of firm $\kappa \in\{1,2\}$ is characterized by a Poisson process $q_{j \kappa}$ in which the arrival rate of innovations, $\Lambda_{j \kappa}$, is in fixed proportion $\lambda$ to the firm's own labor input $l_{j \kappa}$ :

$$
\Lambda_{j \kappa}=\lambda l_{j \kappa} \text { for } j \notin \Theta \text { and } \kappa \in\{1,2\} .
$$

During a short time interval $d \nu$, there is an innovation $d q_{j \kappa}=1$ in firm $\kappa$ with probability $\Lambda_{j \kappa} d \nu$, and no innovation $d q_{j \kappa}=0$ with probability $1-\Lambda_{j \kappa} d \nu$.

\footnotetext{
${ }^{3}$ In papers that consider imitation in a framework with no growth, it is common to measure competition directly by the level of profit [Cf. Kanniainen and Stenbacka (2000)].
} 
In one-leader industry $j \in \Theta$, the representative follower (firm 0) imitates and no firm innovates. The technological change of firm 0 is characterized by a Poisson process $Q_{j}$ in which the arrival rate of imitations is given by

$$
\Gamma_{j}=\gamma l_{j 0}^{1-\varsigma} \ell_{\beta}^{\varsigma} \text { for } j \in \Theta
$$

where $l_{j 0}$ is the firm's own labor input, $\ell_{\beta}$ the average labor input to innovative $R \& D$ in the economy and $\gamma>0$ and $\varsigma \in(0,1)$ are constants. The input $\ell_{\beta}$ characterizes the immediate spillover of knowledge from innovative to imitative R\&D. ${ }^{4}$ During a short time interval $d \nu$, there is an imitation $d Q_{j}=1$ with probability $\Gamma_{j} d \nu$, and no imitation $d Q_{j}=0$ with probability $1-\Gamma_{j} d \nu$.

The invention of a new technology in industry $j$ raises the number of technology in that industry, $t_{j}$, by one and the level of productivity, $B_{j}^{t_{j}}$, by $\mu>1$. Given this and (10), the average productivity in the economy, $B$, is a function of the technologies of all industries, $\left\{t_{k}\right\}$, as follows:

$$
\log B^{\left\{t_{k}\right\}} \doteq \int_{0}^{1} \log B_{j}^{t_{j}} d j, \quad B^{t_{j}+1} / B_{j}^{t_{j}}=\mu
$$

where $\left\{t_{k}\right\}$ denotes a vector that consists of $t_{k}$ for all $k$. The arrival rate of innovations in industry $j \notin \Theta$ is the sum of the arrival rates of both firms in the industry, $\Lambda_{j 1}+\Lambda_{j 2}$. The average growth rate of $B_{j}$ due to technological change in industry $j$ in the stationary state is then given by

$$
E\left[\log B_{j}^{t_{j}+1}-\log B_{j}^{t_{j}}\right]=\left(\Lambda_{j 1}+\Lambda_{j 2}\right) \log \mu,
$$

where $E$ is the expectation operator. ${ }^{5}$ Because only industries $j \notin \Theta$ innovate, then, noting (11), the average growth rate of the average productivity $B$ in the stationary state is given by

$$
\begin{aligned}
g & \doteq \int_{j \notin \Theta} E\left[\log B_{j}^{t_{j}+1}-\log B_{j}^{t_{j}}\right] d j=(\log \mu) \int_{j \notin \Theta}\left(\Lambda_{j 1}+\Lambda_{j 2}\right) d j \\
& =\lambda \int_{j \notin \Theta}\left(l_{j 1}+l_{j 2}\right) d j .
\end{aligned}
$$

\footnotetext{
${ }^{4}$ In the case $\varsigma=0$ investment in imitative R\&D were subject to constant returns to scale and there were no equilibrium for a household (see section 4 and Appendix A, especially equations (45) and (46)). With the spillover effect $\varsigma>0$, the average product of labor in innovative $\mathrm{R} \& \mathrm{D}, \Gamma_{j} / l_{j 0}$, falls with the increase in labor input $l_{j 0}$. This property ensures that a household has an equilibrium.

${ }^{5}$ For this, see Aghion and Howitt (1998), p. 59.
} 
Total employment in $R \& D$ is given by

$$
l \doteq \int_{j \notin \Theta}\left(l_{j 1}+l_{j 2}\right) d j+\int_{j \in \Theta} l_{j} d j .
$$

There exists a fixed number $N$ of households, each supplying one labor unit. Total labor supply $N$ is equal to inputs in production, $x$, and R\&D, $l$ :

$$
N=x+l \text {. }
$$

In industry $j \in \Theta$ firm 0 and in industry $j \notin \Theta$ firms 1 and 2 issue shares to finance their labor expenditure in $R \& D$. Because the households invest in these shares, one obtains

$$
\sum_{\iota=1}^{N} S_{\iota j 0}=w l_{j 0} \text { for } j \in \Theta, \quad \sum_{\iota=1}^{N} S_{\iota j \kappa}=w l_{j \kappa} \text { for } \kappa \in\{1,2\} \text { and } j \notin \Theta
$$

where $w l_{j 0}$ is the imitative expenditure of firm 0 in industry $j \in \Theta, w l_{j \kappa}$ the innovative expenditure of firm $\kappa \in\{1,2\}$ in industry $j \notin \Theta, S_{\iota j 0}\left(S_{\iota j \kappa}\right)$ household $\iota$ 's investment in firm 0 in industry $j \in \Theta$ (firm $\kappa$ in industry $j \notin \Theta)$, and $\sum_{\iota=1}^{N} S_{\iota j 0}\left(\sum_{\iota=1}^{N} S_{\iota j \kappa}\right)$ aggregate investment in firm 0 in industry $j \in \Theta$ (firm $\kappa$ in industry $j \notin \Theta$ ). Household $\iota$ 's relative investment shares in the firms are given by

$$
i_{\iota j 0} \doteq \frac{S_{\iota j 0}}{w l_{j 0}} \text { for } j \in \Theta ; \quad i_{\iota j \kappa} \doteq \frac{S_{\iota j \kappa}}{w l_{j \kappa}} \text { for } j \notin \Theta .
$$

I denote household $\iota$ 's income by $A_{\iota}$. Total income throughout all households $\iota \in\{1, \ldots, N\}$ is then equal to income earned in the production of consumption goods, $P y$, and in R\&D, wl. Since $P y=1$ by (2), this yields

$$
\sum_{\iota=1}^{N} A_{\iota}=P y+w l=1+w l .
$$

\section{Households}

The utility for risk-averting household $\iota \in\{1, \ldots, N\}$ from an infinite stream of consumption beginning at time $T$ is given by

$$
U\left(C_{\iota}, T\right)=E \int_{T}^{\infty} C_{\iota}^{\sigma} e^{-\rho(\nu-T)} d \nu \text { with } 0<\sigma<1 \text { and } \rho>0,
$$


where $\nu$ is time, $E$ the expectation operator, $C_{\iota}$ the index of consumption, $\rho$ the rate of time preference and $1 /(1-\sigma)$ is the constant relative risk aversion.

Because investment in shares in R\&D firms is the only form of saving in the model, the budget constraint of household $\iota$ is given by

$$
A_{\iota}=P C_{\iota}+\int_{j \in \Theta} S_{\iota j 0} d j+\int_{j \notin \Theta}\left(S_{\iota j 1}+S_{\iota j 2}\right) d j
$$

where $A_{\iota}$ is the household's total income, $C_{\iota}$ its consumption, $P$ the consumption price, and $S_{\iota j 0}\left(S_{\iota j \kappa}\right)$ the household's investment in firm 0 in industry $j \in \Theta$ (firm $\kappa$ in industry $j \notin \Theta$ ). When household $\iota$ has financed a successful R\&D firm, it acquires the right to the firm's profit in proportion to its relative investment share. Thus, I define:

$s_{\iota j \kappa}$ household $\iota$ 's true profit from firm $\kappa$ in industry $j$ when the uncertainty in $\mathrm{R} \& \mathrm{D}$ is taken into account;

$i_{\iota j \kappa}$ household $\iota$ 's investment share in firm $\kappa$ in industry $j$ [Cf. (18)];

$\Pi i_{\iota j \kappa}$ household $\iota$ 's expected profit from firm $\kappa \in\{1,2\}$ in industry $j \notin \Theta$ after innovation in firm $\kappa$ have changed the two-leader industry $j$ into a one-leader industry;

$\pi i_{\iota j 0}$ household $\iota$ 's expected profit from firm 0 in industry $j \in \Theta$ after imitation in firm 0 have changed the one-leader industry $j$ into a two-leader industry.

The changes in the profits of firms in industry $j$ are functions of the increments $\left(d q_{j 1}, d q_{j 2}, d Q_{j}\right)$ of Poisson processes $\left(q_{j 1}, q_{j 2}, Q_{j}\right)$ as follows: ${ }^{6}$

$$
\begin{aligned}
& d s_{\iota j \kappa}=\left(\Pi i_{\iota j \kappa}-s_{\iota j \kappa}\right) d q_{j \kappa}-s_{\iota j \kappa} d q_{j(\zeta \neq \kappa)} \text { when } j \notin \Theta ; \\
& d s_{\iota j 0}=\left(\pi i_{\iota j 0}-s_{\iota j 0}\right) d Q_{j} \text { when } j \in \Theta .
\end{aligned}
$$

These functions can be explained as follows. If a household invests in leader $\kappa$ in industry $j \notin \Theta$, then, in the advent of a success for that leader, $d q_{j \kappa}=1$, the amount of its share holdings rises up to $\Pi i_{\iota j \kappa}, d s_{\iota j \kappa}=\Pi i_{\iota j \kappa}-s_{\iota j \kappa}$, but in the advent of success for the other leader $\zeta \neq \kappa$, its share holdings in leader

\footnotetext{
${ }^{6}$ This extends the idea of Wälde (1999a, 1999b).
} 
$\kappa$ fall down to zero, $d s_{\iota j \kappa}=-s_{\iota j \kappa}$. If a household invests in imitating firm 0 in industry $j \in \Theta$, then, in the advent of a success for the firm, $d Q_{j}=1$, the amount of its share holdings rises up to $\pi i_{\iota j 0}, d s_{\iota j 0}=\pi i_{\iota j 0}-s_{\iota j 0}$.

Household $\iota$ 's total income $A_{\iota}$ consists of its wage income $w$ (the household supplies one labor unit), its profits $s_{\iota j 1}$ from the single leader in each industry $j \in \Theta$ and its profits $s_{\iota j 1}$ and $s_{\iota j 2}$ from the two leaders 1 and 2 in each industry $j \notin \Theta$. Given this and (9), one obtains

$$
A_{\iota}=w+\int_{j \in \Theta} s_{\iota j 1} d j+\int_{j \notin \Theta}\left(s_{\iota j 1}+s_{\iota j 2}\right) d j .
$$

Household $\iota$ maximizes its utility (20) by its investment, $\left\{S_{\iota j 0}\right\}$ for $j \in \Theta$ and $\left\{S_{\iota j 1}, S_{\iota j 2}\right\}$ for $j \notin \Theta$, subject to its budget constraint (21), the stochastic changes (22) in its profits, the composition of its income, (23), and the determination of its relative investment shares, (18), given the arrival rates $\left\{\Lambda_{j \kappa}, \Gamma_{j}\right\}$, the wage $w$ and the consumption price $P$. In the households' stationary equilibrium in which the allocation of resources is invariable across technologies, noting (8), (10), this maximization yields (see Appendix A):

$$
\begin{aligned}
& l_{j \kappa}=\ell_{\beta} \quad \text { for } j \notin \Theta, \quad \frac{\ell_{\alpha}}{\ell_{\beta}}=\psi(\pi) \doteq\left[\frac{\pi \gamma / 2}{\Pi \lambda \mu^{\sigma}}\right]^{1 / \varsigma}, \quad \psi^{\prime}=\frac{\psi}{\varsigma \pi}>0, \\
& l_{j 0}=\ell_{\alpha} \text { for } j \in \Theta, \\
& g=\frac{(2 \lambda \log \mu) l}{\alpha \psi /(1-\alpha)+2}, \\
& \rho+\frac{1-\mu^{\sigma}}{\log \mu} g=\Delta(l, \varphi(\alpha, \pi)) \doteq \frac{\lambda \mu^{\sigma} \Pi(N-l)}{\varphi(\alpha, \pi)+\varphi(\alpha, \pi)^{2} l /(N-l)}, \\
& \partial \Delta / \partial l<0, \quad \partial \Delta / \partial \varphi<0 .
\end{aligned}
$$

Result (24) says that with a lower profit $\pi$ investors spend relatively more in innovative than imitative $R \& D$ (i.e. a higher $\ell_{\beta} / \ell_{\alpha}$ ). According to $(25)$, the growth rate $g$ is proportional to labor devoted to R\&D, $l$. Result (26) states that a household's subjective discount factor $\rho+\frac{1-\mu^{\sigma}}{\log \mu} g$ is in equilibrium equal to the rate of return to savings, $\Delta$.

\section{$5 \quad$ General equilibrium}

When an innovation occurs in an industry, this industry switches from the set of two-leader to that of one-leader industries, and when an imitation 
occurs in an industry, this switches from the set of one-leader to that of twoleader industries. In a steady-state equilibrium, every time a new superiorquality product is discovered in some industry, imitation must occur in some other industry. ${ }^{7}$ The rate at which industries leave the group of two-leader industries $k \notin \Theta, \beta\left(\Lambda_{j 1}+\Lambda_{j 2}\right) d \nu$, is then equal to the rate at which the industries leave the group of one-leader industries $j \in \Theta, \alpha \Gamma_{j} d \nu$. This implies

$$
\beta\left(\Lambda_{k 1}+\Lambda_{k 2}\right)=\alpha \Gamma_{j} \text { for } k \notin \Theta \text { and } j \in \Theta .
$$

Given (14), (24) and (27), one obtains that if $\pi=0$, then $\Gamma_{j}=l_{j 0}=\ell_{\alpha}=0$ for $j \in \Theta$ and $g=\Lambda_{k 1}=\Lambda_{k 2}=0$ for $k \notin \Theta$. In other words, without profits in the two-leader industries (i.e. $\pi=0)$, there is no growth $(g=0)$. This result can be rephrased also as follows:

Proposition 1 Some positive profits $\pi>0$ in the two-leader industries are necessary for growth $g>0$.

With non-diversifiable risk, households hold the shares of all innovating firms in their portfolios. Given this, they have no incentives to invest in imitating R\&D unless there are profits during the innovation race. Without imitation, all firms will end up in the set of one-leader industries. This means that there will be no firms to innovate and no growth.

Equations (8), (11), (12), (24) and (27) yield

$$
\begin{aligned}
\frac{\alpha}{1-\alpha} & =\frac{\alpha}{\beta}=\frac{\Lambda_{j 1}+\Lambda_{j 2}}{\Gamma_{j}}=\frac{\lambda\left(l_{j 1}^{1-\varsigma}+l_{j 2}^{1-\varsigma}\right)}{\gamma l_{j 0}^{1-\varsigma}}=\frac{2 \lambda \ell_{\beta}^{1-\varsigma}}{\gamma \ell_{\alpha}^{1-\varsigma}}=\frac{2 \lambda}{\gamma \psi} \psi^{\varsigma}=\frac{\pi \mu^{-\sigma}}{\Pi \psi} \\
& =(2 \lambda / \gamma)^{1 / \varsigma}\left(\Pi \mu^{\sigma}\right)^{1 / \varsigma-1} \pi^{1-1 / \varsigma} .
\end{aligned}
$$

Inserting this into (25), one obtains that the ratio of the growth rate to labor devoted to R\&D, $g / l$, falls with a higher profit in the two-leader industries:

$$
g=\epsilon(\pi) l, \quad \epsilon(\pi) \doteq \frac{2 \lambda \log \mu}{\mu^{-\sigma} \pi / \Pi+2}, \quad \epsilon^{\prime}<0 .
$$

The two equations (26) and (29) form a system of two unknowns $(l, g)$. Unfortunately, these results are ambiguous, because an increase in the growth rate $g$ lowers both a household's subjective discount factor $\rho+\frac{1-\mu^{\sigma}}{\log \mu} g$ and the

${ }^{7}$ Cf. Segerstrom (1991), p. 817. 
rate of return to savings, $\Delta$, through lower employment $l$ in $R \& D$. For this reason, I assume the following stability property for the equation (29). ${ }^{8}$ After a small perturbation, the actual growth rate of the economy, $g$, adjusts to its stationary equilibrium level according to

$$
d g / d \nu=\delta(\epsilon(\pi) l-g) \text { with } \delta^{\prime}>0,
$$

where $\nu$ is time and $\delta$ a differentiable function. Noting (8), (10), (24) and (30), and differentiating the equation (26) totally, one can in equilibrium with $d g / d \nu=0$ define the function [Appendix B]

$$
\begin{aligned}
& g(\pi, \varphi(\alpha, \pi)), \quad \frac{\partial g}{\partial \pi}<0, \quad \frac{\partial g}{\partial \varphi}<0, \quad \frac{\partial g}{\partial \varphi} \frac{\partial \varphi}{\partial \beta}=-\frac{\partial g}{\partial \varphi} \frac{\partial \varphi}{\partial \alpha}<0 \\
& \left.\frac{\partial g}{\partial \varphi} \frac{d \varphi}{d \pi}\right|_{\pi>\pi_{0}}>0,\left.\quad \frac{\partial g}{\partial \varphi} \frac{d \varphi}{d \pi}\right|_{\pi<\pi_{0}}<0,\left.\quad \frac{d g}{d \pi}\right|_{\pi<\pi_{0}}=\left[\frac{\partial g}{\partial \pi}+\frac{\partial g}{\partial \varphi} \frac{d \varphi}{d \pi}\right]_{\pi<\pi_{0}}<0
\end{aligned}
$$

The results (31) can be rephrased as follows:

Proposition 2 The proportion $\beta$ of industries subject to price competition is negatively associated with the growth rate $g$. An increase in product market competition (i.e. a decrease in $\pi$ ) promotes growth when the initial level of competition is high enough (i.e. $\pi<\pi_{0}$ ).

A higher proportion of two-leader industries raises the demand for labor in production. This decreases labor devoted to $\mathrm{R} \& \mathrm{D}$ and the growth rate. An increase in product market competition leads to faster growth through the competition-escaping effect. Households, which hold the shares of both leaders in their portfolios, attempt to get rid of competition by investing in $R \& D$ in both firms. In the case of successful innovation by either of the leaders, they get a higher profit from the remaining leader than from the two leaders before the innovation. On the other hand, an increase in competition leads to to slower growth through the wage effect as follows. With competition the leaders charge lower prices, produce more and employ more labor in production. This transfers labor from R\&D into production, and the growth rate falls. The competition-escaping effect dominates at high initial levels of product market competition.

\footnotetext{
${ }^{8}$ Cf. Dixit (1986), for the use of stability properties in refining comparative statics.
} 


\section{Conclusions}

This paper examines a multi-industry economy in which growth is generated by creative destruction. In each industry, a firm creating the newest technology by a successful innovative R\&D project crowds out the other firms with older technologies from the market and becomes the first leader of the industry. A firm creating a copy of the newest technology starts producing a close substitute for the innovator's product and establishes an innovation race with the first leader. Because there is systematic investment risk that cannot be eliminated by diversification, the households hold the shares of all firms in their portfolios.

In this paper, I show that an increase in product market competition (as measured by the elasticity or product substitution) speeds up growth through the competition-escaping effect. Households, which hold the shares of both leaders in their portfolios, attempt to get rid of competition by investing in R\&D in both firms. In the case of successful innovation by either of the leaders, they get a higher profit from the remaining leader than from the two leaders before the innovation. On the other hand, an increase in competition hampers growth through the wage effect as follows. With competition the leaders charge lower prices, produce more and employ more labor in production. This transfers labor from R\&D into production, and the growth rate falls. The competition-escaping effect dominates at high initial levels of competition. In Aghion et al. (1997, 2001), the utility function is linear in labor so that there is an infinite supply of labor at a given wage. Thus, in their model there is only the competition-escaping but no wage effect, and competition is unambiguously growth promoting.

Note that the competition-escaping effect in this paper differs from that in the earlier product-cycle models which assume diversifiable risk as follows. ${ }^{9}$ With diversifiable risk, firms choose their optimal inputs to R\&D at a given market interest rate. In such a case, the two competing leaders in a market attempt to get rid of each other by investing in R\&D. With nondiversifiable risk, households make investment decisions by purhasing shares of R\&D firms. Thus, they purchase the shares of both leaders in other to earn higher profit from one leader after a successful innovation by either of

\footnotetext{
${ }^{9}$ Cf. [e.g. Aghion et al. (1997, 2001).
} 
the leaders than from the two leaders before. In both cases, however, the competition-escaping effect leads to a higher growth rate of the economy.

Mukoyama (2003) argues that in the presence of fully diversifiable risk firms imitate in order to be able to participate in the innovation race, although during the race they had no profits. I show that this does not hold with non-diversifiable risk. Because the households hold shares of all innovating firms in the same portfolios, they have no incentives to invest in imitating R\&D unless there are profits during the innovation race. Mukoyama (2003) shows that in the presence of diversifiable risk there are cases where the proportion of industries subject to price competition and the growth rate are positively correlated. I show that with non-diversifiable risk this is vice versa. An increase in the proportion of industries that have more than one producer raises the demand for labor in production. This decreases labor devoted to $\mathrm{R} \& \mathrm{D}$ and the growth rate.

\section{Appendix}

A. Results (24)-(25)

I denote:

$\Omega\left(\left\{s_{\iota k v}\right\},\left\{t_{k}\right\}\right)$ the value of receiving profits $s_{\iota k v}$ from all firms $v$ in all industries $k$ using current technology $t_{k}$.

$\Omega\left(\Pi i_{\iota j \kappa}, 0,\left\{s_{\iota(k \neq j) v}\right\}, t_{j}+1,\left\{t_{k \neq j}\right\}\right)$ the value of receiving the profit $\Pi i_{\iota j \kappa}$ from firm $\kappa$ in industry $j \notin \Theta$ using technology $t_{j}+1$, but receiving no profits from the other firm which was a leader in that industry when technology $t_{j}$ was used, and receiving profits $s_{\iota(k \neq j) v}$ from all firms $v$ in other industries $k \neq j$ with current technology $t_{k}$.

$\Omega\left(\pi i_{\iota j 1}, \pi i_{\iota j 2},\left\{s_{\iota(k \neq j) v}\right\},\left\{t_{k}\right\}\right)$ the value of receiving profits $\pi i_{\iota j \kappa}$ from firms $\kappa \in\{1,2\}$ in industry $j \in \Theta$, but receiving profits $s_{\iota(k \neq j) v}$ from all firms $v$ in the other industries $k \neq j$ with current technology $t_{k}$.

The Bellman equation associated with the household's maximization is ${ }^{10}$

$$
\rho \Omega\left(\left\{s_{\iota k v}\right\},\left\{t_{k}\right\}\right)=\max _{S_{\iota j} \geq 0 \text { for all } j} \Xi_{\iota},
$$

${ }^{10} \mathrm{Cf}$. Dixit and Pindyck (1994). 
where

$$
\begin{aligned}
& \Xi_{\iota} \doteq C_{\iota}^{\sigma}+\int_{j \in \Theta} \Gamma_{j}\left[\Omega\left(\pi i_{\iota j 1}, \pi i_{\iota j 1},\left\{s_{\iota(k \neq j) v}\right\},\left\{t_{k}\right\}\right)-\Omega\left(\left\{s_{\iota k v}\right\},\left\{t_{k}\right\}\right)\right] d j \\
& +\int_{j \notin \Theta} \sum_{\kappa=1,2} \Lambda_{j \kappa}\left[\Omega\left(\Pi i_{\iota j \kappa}, 0,\left\{s_{\iota(k \neq j) v}\right\}, t_{j}+1,\left\{t_{k \neq j}\right\}\right)-\Omega\left(\left\{s_{\iota k v}\right\},\left\{t_{k}\right\}\right)\right] d j .
\end{aligned}
$$

Because $\partial C_{\iota} / \partial S_{\iota j \kappa}=-1 / P$ by $(21)$, the first-order conditions are given by

$$
\begin{gathered}
\Lambda_{j \kappa} \frac{d}{d S_{\iota j \kappa}}\left[\Omega\left(\Pi i_{\iota j \kappa}, 0,\left\{s_{\iota(k \neq j) v}\right\}, t_{j}+1,\left\{t_{k \neq j}\right\}\right)-\Omega\left(\left\{s_{\iota k v}\right\},\left\{t_{k}\right\}\right)\right]=\frac{\sigma}{P} C_{\iota}^{\sigma-1} \\
\text { for } j \notin \Theta \text { and } \kappa \in\{1,2\}, \\
\Gamma_{j} \frac{d}{d S_{\iota j 0}}\left[\Omega\left(\pi i_{\iota j 1}, \pi i_{\iota j 2},\left\{s_{\iota(k \neq j) v}\right\},\left\{t_{k}\right\}\right)-\Omega\left(\left\{s_{\iota k v}\right\},\left\{t_{k}\right\}\right)\right]=\frac{\sigma}{P} C_{\iota}^{\sigma-1} \\
\quad \text { for } j \in \Theta .
\end{gathered}
$$

I try the solution that for each household $\iota$ the propensity to consume, $h_{\iota}$, and the subjective interest rate $r_{\iota}$ are independent of income $A_{\iota}$, i.e. $P C_{\iota}=h_{\iota} A_{\iota}$ and $\Omega=C_{\iota}^{\sigma} / r_{\iota}$. Let us denote variables depending on technology $t_{k}$ by superscript $t_{k}$. Since according to (23) income $A_{\iota}^{\left\{t_{k}\right\}}$ depends directly on variables $\left\{s_{\iota k}^{t_{k}}\right\}$, I denote $A_{\iota}^{\left\{t_{k}\right\}}\left(\left\{s_{\iota k}^{t_{k}}\right\}\right)$. Assuming that $h_{\iota}$ is invariant across technologies yields

$$
P^{\left\{t_{k}\right\}} C_{\iota}^{\left\{t_{k}\right\}}=h_{\iota} A_{\iota}^{\left\{t_{k}\right\}}\left(\left\{s_{\iota k}^{t_{k}}\right\}\right)
$$

The share in the next innovator $t_{j}+1$ is determined by investment under the present technology $t_{j}, s_{\iota j \kappa}^{t_{j}+1}=\Pi i_{\iota j \kappa}^{t_{j}}$ for $j \notin \Theta$. The share in the next imitator is determined by investment under the same technology $t_{j}, s_{\iota j \kappa}^{t_{j}}=\pi i_{\iota j \kappa}^{t_{j}}$ for $j \in \Theta$. The value functions are then given by

$$
\begin{aligned}
& \Omega\left(\left\{s_{\iota k v}\right\},\left\{t_{k}\right\}\right)=\Omega\left(\pi i_{\iota j 1}, \pi i_{\iota j 2},\left\{s_{\iota(k \neq j) v}\right\},\left\{t_{k}\right\}\right)=\frac{1}{r_{\iota}}\left(C_{\iota}^{\left\{t_{k}\right\}}\right)^{\sigma}, \\
& \Omega\left(\Pi i_{\iota j \kappa}, 0,\left\{s_{\iota(k \neq j) v}\right\}, t_{j}+1,\left\{t_{k \neq j}\right\}\right)=\frac{1}{r_{\iota}}\left(C_{\iota}^{t_{j}+1,\left\{t_{k \neq j}\right\}}\right)^{\sigma} .
\end{aligned}
$$

Given this, one obtains

$$
\frac{\partial \Omega\left(\left\{s_{\iota k v}\right\},\left\{t_{k}\right\}\right)}{\partial S_{\iota j}^{t_{j}}}=0
$$


From (18), (23), (36), (37), $s_{\iota j \kappa}^{t_{j}+1}=\Pi i_{\iota j \kappa}^{t_{j}}$ for $j \notin \Theta$, and $s_{\iota j \kappa}^{t_{j}}=\pi i_{\iota j \kappa}^{t_{j}}$ for $j \in \Theta$ it follows that

$$
\begin{aligned}
& \frac{\partial s_{\iota j \kappa}^{t_{j}+1}}{\partial i_{\iota j \kappa}^{t_{j}}}=\Pi \text { for } j \notin \Theta, \quad \frac{\partial s_{\iota j 0}^{t_{j}}}{\partial i_{\iota j 0}^{t_{j}}}=\pi \text { for } j \in \Theta, \quad \frac{\partial A_{\iota}^{t_{j}+1,\left\{t_{k \neq j}\right\}}}{\partial s_{\iota j \kappa}^{t_{j}+1}}=\frac{\partial A_{\iota}^{\left\{t_{k}\right\}}}{\partial s_{\iota j \kappa}^{t_{j}}}=1 \text {, } \\
& \frac{\partial i_{\iota j 0}^{t_{j}}}{\partial S_{\iota j 0}^{t_{j}}}=\frac{1}{w^{\left\{t_{k}\right\}} l_{j 0}^{\left\{t_{k}\right\}}} \text { for } j \in \Theta, \frac{\partial i_{\iota j \kappa}^{t_{j}}}{\partial S_{\iota j \kappa}^{t_{j}}}=\frac{1}{w^{\left\{t_{k}\right\}} l_{j \kappa}^{\left\{t_{k}\right\}}} \text { for } j \notin \Theta, \\
& \frac{\partial \Omega\left(\Pi i_{\iota j \kappa}, 0,\left\{s_{\iota(k \neq j) v}\right\}, t_{j}+1,\left\{t_{k \neq j}\right\}\right)}{\partial S_{\iota j \kappa}^{t_{j}}} \\
& =\frac{\sigma}{r_{\iota}}\left(C_{\iota}^{t_{j}+1,\left\{t_{k \neq j}\right\}}\right)^{\sigma-1} \underbrace{\frac{\partial C_{\iota}^{t_{j}+1,\left\{t_{k \neq j}\right\}}}{\partial A_{\iota}^{t_{j}+1,\left\{t_{k \neq j}\right\}}}}_{h_{\iota} / P^{t_{j}+1,\left\{t_{k \neq j}\right\}}} \underbrace{\frac{\partial A_{\iota}^{t_{j}+1,\left\{t_{k \neq j}\right\}}}{\partial s_{\iota j \kappa}^{t_{j}+1}}}_{=1} \underbrace{\frac{\partial s_{\iota j \kappa}^{t_{j}+1}}{\partial i_{i j \kappa}^{t_{j}}}}_{=\pi} \frac{\partial i_{\iota j \kappa}^{t_{j}}}{\partial S_{\iota j \kappa}^{t_{j}}} \\
& =\frac{\prod \sigma h_{\iota}\left(C_{\iota}^{t_{j}+1,\left\{t_{k \neq j}\right\}}\right)^{\sigma-1}}{r_{\iota} P^{t_{j}+1,\left\{t_{k \neq j}\right\}}} \frac{\partial i_{\iota j \kappa}^{t_{j}}}{\partial S_{\iota j \kappa}^{t_{j}}}=\frac{\prod h_{\iota} \sigma\left(C_{\iota}^{t_{j}+1,\left\{t_{k \neq j}\right\}}\right)^{\sigma-1}}{r_{\iota} w^{\left\{t_{k}\right\}} P^{t_{j}+1,\left\{t_{k \neq j}\right\}} l_{j \kappa}^{\left\{t_{k}\right\}}} \quad \text { for } j \notin \Theta, \\
& \frac{\partial \Omega\left(\pi i_{\iota j 1}, \pi i_{\iota j 2},\left\{s_{\iota(k \neq j) v}\right\},\left\{t_{k}\right\}\right)}{\partial S_{\iota j 0}^{t_{j}}}=\frac{\sigma}{r_{\iota}}\left(C_{\iota}^{\left\{t_{k}\right\}}\right)^{\sigma-1} \underbrace{\frac{\partial C_{\iota}^{\left\{t_{k}\right\}}}{\partial A_{\iota}^{\left\{t_{k}\right\}}}}_{=h_{\iota} / P^{\left\{t_{k}\right\}}} \underbrace{\frac{\partial A_{\iota}^{\left\{t_{k}\right\}}}{s_{\iota j 0}^{t_{j}}}}_{=1} \underbrace{\frac{s_{\iota j 0}^{t_{j}}}{\partial i_{\iota j 0}^{t}}}_{=\pi} \frac{\partial i_{\iota j 0}^{t}}{\partial S_{\iota j 0}^{t}} \\
& =\frac{\pi \sigma h_{\iota}}{r_{\iota} P^{\left\{t_{k}\right\}}}\left(C_{\iota}^{\left\{t_{k}\right\}}\right)^{\sigma-1} \frac{\partial i_{\iota j 0}^{t}}{\partial S_{\iota j 0}^{t}}=\frac{\pi h_{\iota} \sigma\left(C_{\iota}^{\left\{t_{k}\right\}}\right)^{\sigma-1}}{r_{\iota} w^{\left\{t_{k}\right\}} P^{\left\{t_{k}\right\}} l_{j 0}^{\left\{t_{k}\right\}}} \quad \text { for } j \in \Theta \text {. }
\end{aligned}
$$

I focus on a stationary equilibrium where the growth rate $g$ and the allocation of labor, $\left(l_{j \kappa}, x\right)$, are invariant across technologies. Given (2), (10), (13) and (16), this implies

$$
\begin{aligned}
& l_{j \kappa}^{\left\{t_{k}\right\}}=l_{j \kappa}, \quad x^{\left\{t_{k}\right\}}=x=N-l, \quad w^{\left\{t_{k}\right\}}=w=x / \varphi, \\
& \frac{P^{\left\{t_{k}\right\}}}{P^{t_{j}+1,\left\{t_{k \neq j}\right\}}}=\frac{C_{\iota}^{t_{j}+1,\left\{t_{k \neq j}\right\}}}{C_{\iota}^{\left\{t_{k}\right\}}}=\frac{A_{\iota}^{t_{j}+1,\left\{t_{k \neq j}\right\}}}{A_{\iota}^{\left\{t_{k}\right\}}}=\frac{y^{t_{j}+1,\left\{t_{k \neq j}\right\}}}{y^{\left\{t_{k}\right\}}}=\frac{B^{t_{j}+1,\left\{t_{k \neq j}\right\}}}{B^{\left\{t_{k}\right\}}}=\mu .
\end{aligned}
$$

Inserting (14), (33), (36), (37), (41) and $g \doteq \int_{j \notin \Theta} l_{j} d j$ into (32) yields

$$
\begin{aligned}
0= & {\left[\rho+\int_{j \notin \Theta}\left(\Lambda_{j 1}+\Lambda_{j 2}\right) d j+\int_{j \in \Theta} \Gamma_{j} d j\right] \Omega\left(\left\{s_{\iota k v}\right\},\left\{t_{k}\right\}\right)-\left(C_{\iota}^{\left\{t_{k}\right\}}\right)^{\sigma} } \\
& -\int_{j \notin \Theta} \sum_{\kappa=1,2} \Lambda_{j \kappa} \Omega\left(\Pi i_{\iota j \kappa}, 0,\left\{s_{\iota(k \neq j) v}\right\}, t_{j}+1,\left\{t_{k \neq j}\right\}\right) d j
\end{aligned}
$$




$$
\begin{aligned}
& -\int_{j \in \Theta} \Gamma_{j} \Omega\left(\pi i_{\iota j 1}, \pi i_{\iota j 2},\left\{s_{\iota(k \neq j) v}\right\},\left\{t_{k}\right\}\right) d j \\
= & {\left[\rho+\int_{j \notin \Theta}\left(\Lambda_{j 1}+\Lambda_{j 2}\right) d j\right] \frac{\left(C_{\iota}^{\left\{t_{k}\right\}}\right)^{\sigma}}{r_{\iota}}-\left(C_{\iota}^{\left\{t_{k}\right\}}\right)^{\sigma} } \\
& -\int_{j \notin \Theta} \sum_{\kappa=1,2} \frac{\Lambda_{j \kappa}}{r_{\iota}}\left(C_{\iota}^{\left\{t_{j}+1\right\},\left\{t_{k \neq j}\right\}}\right)^{\sigma} d j \\
= & {\left[\rho+\int_{j \notin \Theta}\left(\Lambda_{j 1}+\Lambda_{j 2}\right) d j\right] \frac{\left(C_{\iota}^{\left\{t_{k}\right\}}\right)^{\sigma}}{r_{\iota}}-\left(C_{\iota}^{\left\{t_{k}\right\}}\right)^{\sigma}-\int_{j \notin \Theta} \sum_{\kappa=1,2} \Lambda_{j \kappa} \frac{\mu^{\sigma}}{r_{\iota}}\left(C_{\iota}^{\left\{t_{k}\right\}}\right)^{\sigma} d j } \\
= & \frac{1}{r_{\iota}}\left(C_{\iota}^{\left\{t_{k}\right\}}\right)^{\sigma}\left[\rho+\left(1-\mu^{\sigma}\right) \int_{j \notin \Theta}\left(\Lambda_{j 1}+\Lambda_{j 2}\right) d j-r_{\iota}\right] \\
= & \frac{1}{r_{\iota}}\left(C_{\iota}^{\left\{t_{k}\right\}}\right)^{\sigma}\left[\rho-r_{\iota}+\frac{1-\mu^{\sigma}}{\log \mu} g\right] .
\end{aligned}
$$

This equation is equivalent to

$$
r_{\iota}=\rho+\frac{1-\mu^{\sigma}}{\log \mu} g
$$

Because there is symmetry throughout all households $\iota$, their propensity to consume is equal, $h_{\iota}=h$. This, (17), (19), (21), (23) and (36) yield

$$
\begin{aligned}
w l & =w \int_{j \in \Theta} l_{j 0} d j+w \int_{j \notin \Theta}\left(l_{j 1}+l_{j 2}\right) d j=w \int_{j \in \Theta} l_{j 0} d j+\int_{j \notin \Theta}\left(l_{j 1}+l_{j 2}\right) d j \\
& =\sum_{\iota=1}^{N}\left[\int_{j \in \Theta} S_{\iota j 0} d j+\int_{j \notin \Theta}\left(S_{\iota j 1}+S_{\iota j 2}\right) d j\right]=\sum_{\iota=1}^{N}\left(A_{\iota}-P C_{\iota}\right) \\
& =(1-h) \sum_{\iota=1}^{N} A_{\iota}=(1-h)(1+w l) .
\end{aligned}
$$

Solving for the propensity to consume, one obtains

$$
h_{\iota}=h=(1+w l)^{-1} .
$$

Given (10) and (16), one obtains the wage

$$
w=\varphi / x=\varphi(\alpha, \pi) /(N-l) .
$$

I define the rate of return to imitative $\mathrm{R} \& \mathrm{D}$ by $z \doteq \pi \Gamma_{j} /\left(w l_{j 0}\right)$. Inserting 
this, (9), (11), (12), (38), (39) and (40) into (34) and (35), one obtains

$$
\begin{aligned}
& \frac{\Pi h \sigma \mu^{\sigma}\left(C_{\iota}^{\left\{t_{k}\right\}}\right)^{\sigma-1} \lambda}{\left(\rho+\frac{1-\mu^{\sigma}}{\log \mu} g\right) w P^{\left\{t_{k}\right\}}}=\frac{\sigma \Pi h_{\iota} \mu^{\sigma} \Lambda_{j \kappa}\left(C_{\iota}^{\left\{t_{k}\right\}}\right)^{\sigma-1}}{r_{\iota} w l_{j \kappa} P^{\left\{t_{k}\right\}}} \\
& =\frac{\sigma \Pi h_{\iota} \Lambda_{j \kappa}\left(C_{\iota}^{t_{j}+1,\left\{t_{k \neq j}\right\}}\right)^{\sigma-1}}{r_{\iota} w l_{j \kappa} P^{t_{j}+1,\left\{t_{k \neq j}\right\}}}=\Lambda_{j \kappa} \frac{d}{d S_{\iota j \kappa}} \Omega\left(\Pi i_{\iota j},\left\{s_{\iota}(k \neq j)\right\}, t_{j}+1,\left\{t_{k \neq j}\right\}\right) \\
& =\frac{\sigma}{P^{\left\{t_{k}\right\}}}\left(C_{\iota}^{\left\{t_{k}\right\}}\right)^{\sigma-1} \text { for } j \notin \Theta \text { and } \kappa \in\{1,2\} \\
& \frac{\pi h \sigma\left(C_{\iota}^{\left\{t_{k}\right\}}\right)^{\sigma-1} \gamma l_{j 0}^{-\varsigma} \ell_{\beta}^{\varsigma}}{\left(\rho+\frac{1-\mu^{\sigma}}{\log \mu} g\right) w P^{\left\{t_{k}\right\}}}=\frac{\sigma h\left(C_{\iota}^{\left\{t_{k}\right\}}\right)^{\sigma-1} z}{r_{\iota} w l_{j 0} P^{\left\{t_{k}\right\}}}=\frac{\sigma \pi h_{\iota} \Gamma_{j}\left(C_{\iota}^{\left\{t_{k}\right\}}\right)^{\sigma-1}}{r_{\iota} w l_{j 0} P^{\left\{t_{k}\right\}}} \\
& =\Gamma_{j} \frac{d}{d S_{\iota j 0}} \Omega\left(\left\{\pi i_{\iota j 1}, \pi i_{\iota j 2},\left\{s_{\iota m(k \neq j)}\right\},\left\{t_{k}\right\}\right)=\frac{\sigma}{P^{\left\{t_{k}\right\}}}\left(C_{\iota}^{\left\{t_{k}\right\}}\right)^{\sigma-1} \text { for } j \in \Theta .\right.
\end{aligned}
$$

Given equations (45) and (46) and (9), one obtains

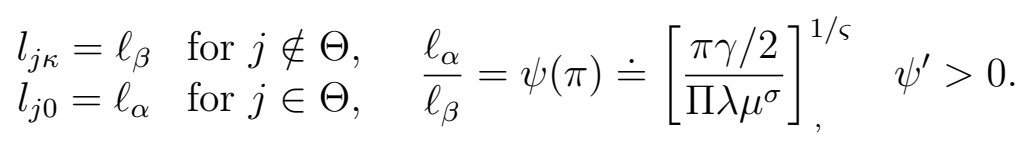

Equations (2), (8), (11), (14), (15), (43), (44), (46) and (47) yield

$$
\begin{gathered}
l=\int_{j \notin \Theta}\left(l_{j 1}+l_{j 2}\right) d j+\int_{j \in \Theta} l_{j} d j=\ell_{\beta} \int_{j \notin \Theta} d j+\ell_{\alpha} \int_{j \in \Theta} d j \\
=\alpha \ell_{\alpha}+2(1-\alpha) \ell_{\beta}=[\alpha \psi+2(1-\alpha)] \ell_{\beta}, \\
\ell_{\beta}=[\alpha \psi+2(1-\alpha)]^{-1} l, \quad \ell_{\alpha}=[\alpha \psi+2(1-\alpha)]^{-1} \psi l, \\
\Lambda_{j \kappa}=\lambda \ell_{\beta}=\lambda[\alpha \psi+2(1-\alpha)]^{-1} l \text { for } j \notin \Theta \text { and } \kappa \in\{1,2\}, \\
g=(\log \mu) \int_{j \notin \Theta}\left(\Lambda_{j 1}+\Lambda_{j 2}\right) d j=(2 \log \mu)(1-\alpha) \Lambda_{j \kappa} \\
=\frac{(2 \lambda \log \mu)(1-\alpha) l}{\alpha \psi+2(1-\alpha)}=\frac{(2 \lambda \log \mu) l}{\alpha \psi /(1-\alpha)+2}, \\
\rho+\frac{1-\mu^{\sigma}}{\log \mu} g=\frac{h \mu^{\sigma} \Pi \Lambda_{j \kappa}}{w l_{j \kappa}}=\frac{\lambda h \mu^{\sigma} \Pi}{w}=\frac{\lambda \mu^{\sigma} \Pi}{w(1+w l)}=\frac{\lambda \mu^{\sigma} \Pi}{w+w^{2} l} \\
=\frac{\lambda \mu^{\sigma} \Pi(N-l)}{\varphi(\alpha, \pi)+\varphi(\alpha, \pi)^{2} l /(N-l)} .
\end{gathered}
$$

Equations (44), (47), (48) and (49) define (24)-(25). 


\section{B. Results (31)}

The equation (26) defines the function $l(g, \varphi(\alpha, \pi))$ with the properties

$$
\frac{\partial l}{\partial g}=\underbrace{\frac{1-\mu^{\sigma}}{\log \mu}}_{-} / \underbrace{\frac{\partial \Delta}{\partial l}}_{-}>0, \quad \frac{\partial l}{\partial \varphi}=-\underbrace{\frac{\partial \Delta}{\partial \varphi}}_{-} / \underbrace{\frac{\partial \Delta}{\partial l}}_{-}<0 .
$$

Inserting this into the differential equation (30) yields

$$
d g / d \nu=\Upsilon(g, \pi, \varphi(\alpha, \pi)) \doteq \delta(\epsilon(\pi) l(g, \varphi(\alpha, \pi))-g) \text { with } \delta^{\prime}>0,
$$

where the stability requires $\partial \Upsilon / \partial g<0$. Noting (29), (50) and (51), one obtains

$$
\frac{\partial \Upsilon}{\partial \pi}=\delta^{\prime} \epsilon^{\prime} l<0, \quad \frac{\partial \Upsilon}{\partial \varphi}=\delta^{\prime} \frac{\partial l}{\partial \varphi}<0 .
$$

Thus, in equilibrium with $d g / d \nu=0$ in (51), one can define the function

$$
g(\pi, \varphi(\alpha, \pi)), \quad \frac{\partial g}{\partial \pi}=-\frac{\partial \Upsilon}{\partial \pi} / \frac{\partial \Upsilon}{\partial g}<0, \quad \frac{\partial g}{\partial \varphi}=-\frac{\partial \Upsilon}{\partial \varphi} / \frac{\partial \Upsilon}{\partial g}<0
$$

The equation (28) defines the proportion of one-leader industries, $\alpha$, as a decreasing function of the profit in the two-leader industries, $\pi$ :

$$
\alpha(\pi), \quad \alpha^{\prime}=\alpha(1-\alpha)(1-1 / \varsigma) / \pi<0, \quad \lim _{\pi \rightarrow 0} \alpha=1 .
$$

Finally, given (10), (24) and (53), one obtains that wage expenditure in production, $w x=\varphi$, depends on the profit $\pi$ as follows:

$$
\begin{aligned}
\frac{d \varphi}{d \pi} & =\frac{\partial \varphi}{\partial \alpha} \alpha^{\prime}+\frac{\partial \varphi}{\partial \pi}=(2 \pi-\Pi) \alpha^{\prime}+2(\alpha-1) \\
& =(1-\alpha)[(1 / \varsigma-1)(\Pi-2 \pi) \alpha(\pi)-2 \pi] / \pi .
\end{aligned}
$$

This implies

$$
\begin{aligned}
& \frac{d \varphi}{d \pi}<0 \text { for } \pi>\pi_{0}, \quad \frac{d \varphi}{d \pi}>0 \text { for } \pi<\pi_{0}, \quad \lim _{\pi \rightarrow \Pi / 2} \frac{d \varphi}{d \pi}=\alpha-1<0, \\
& \lim _{\pi \rightarrow 0} \frac{d \varphi}{d \pi}=\frac{1-\alpha}{\pi} \lim _{\pi \rightarrow 0, \alpha \rightarrow 1}\left[\left(\frac{1}{\varsigma}-1\right)(\Pi-2 \pi) \alpha-2 \pi\right]=\frac{1-\alpha}{\pi}\left(\frac{1}{\varsigma}-1\right) \Pi>0,
\end{aligned}
$$

where the constant $\pi_{0} \in(1, \mu)$ is defined by the equation

$$
(1 / \varsigma-1)\left(\Pi / \pi_{0}-2\right) \alpha\left(\pi_{0}\right)=2 .
$$

Inserting (54) into (52) yields (31). 


\section{References:}

Aghion, P., Harris, C. and Vickers, J. (1997). Competition and growth with step-by-step innovation: an example. European Economic Review 41, 771-782.

Aghion, P., Harris, C., Howitt, P. and Vickers, J. (2001). Competition, Imitation and growth with step-by-step innovation. Review of Economic Studies 68, 467-492.

Aghion, P. and Howitt, P. (1998). Endogenous Growth Theory. Cambridge (Mass.): MIT Press.

Barro, R.J. and Sala-i-Martin, X. (1995). Economic Growth. New York: MacGraw-Hill.

Cheng, L.K. and Tao, Z. (1999). The impact of public policies on innovation and imitation: the role of $\mathrm{R} \& \mathrm{D}$ technology in growth models. International Economic Review 40, 187-207.

Dixit, A. (1986). Comparative statics for oligopoly. International Economic Review 27), 107-122.

Dixit, A. and Pindyck, K. (1994). Investment under Uncertainty. Princeton: Princeton University Press.

Kanniainen, V. and Stenbacka, R. (2000). Endogenous imitation and implications for technology policy. Journal of Institutional and Theoretical Economics 156, 360-381.

Mukoyama, T. (2003). Innovation, imitation, and growth with cumulative technology. Journal of Monetary Economics 50, 361-380.

Segerstrom, P.S. (1991). Innovation, imitation, and economic growth. Journal of Political Economy 99, 807-827.

Wälde, K. (1999a). A model of creative destruction with undiversifiable risk and optimizing households. The Economic Journal 109, C156-C171.

Wälde, K., (1999b). Optimal saving under Poisson uncertainty. Journal of Economic Theory 87, 194-217. 